* O texto deste artigo reúne e reorganiza, de forma particular e autorizada, vários relatórios da nossa pesquisa sobre 'As grandes transformações contemporâneas do sistema mundial', que vêm sendo desenvolvidos e publicados na forma de textos autônomos pelo INEEP, Instituto de Estudos Estratégicos do Petróleo, Gás e Biocombustíveis, disponíveis em: < $w w w$. ineep.org.br/jose-luisisfiori>.

\title{
Geopolítica internacional: a nova estratégia imperial dos Estados Unidos*
}

\author{
International geopolitics: the new imperial strategy of the United \\ States
}

José Luís da Costa Fiori

DOI: 10.1590/0103-110420185301

\begin{abstract}
O aparecimento de uma potência emergente é sempre um fator de desestabilização e mudança do sistema mundial, porque sua ascensão ameaça o monopólio das potências estabelecidas. Na verdade, porém, os grandes desestabilizadores do sistema são os próprios Estados líderes ou hegemônicos, pois eles não podem parar de se expandir para manterem sua hegemonia - e para se manterem à frente dos demais, eles precisam desafiar continuamente as regras e instituições que foram estabelecidas por eles mesmos, mas que podem estar bloqueando sua necessidade de inovar e expandir mais do que todos os demais ${ }^{\mathbf{1 ( 3 0 - 3 1 )}}$. (José Luís da Costa Fiori)
\end{abstract}

\section{Introdução}

Este artigo se propõe fazer uma fotografia rápida, quase instantânea, da geopolítica internacional de meados de 2018. Deve-se saber, desde logo, que é quase impossível que uma fotografia desse tipo consiga incluir todos os tabuleiros, conflitos e contradições de uma conjuntura que vem se caracterizando pela rapidez e radicalidade de suas rupturas e transformações. Por isso, em um artigo desta extensão, fomos obrigados a fazer escolhas e tomar decisões que deixaram de lado muitas coisas relevantes que estão acontecendo neste momento ao redor do mundo. Decidimos centrar nossa atenção no epicentro do tsunami: a luta interna do establishment americano e o 'fenômeno Trump'; a nova 'doutrina de segurança nacional' dos Estados Unidos da América (EUA) e seus impactos na relação entre as três grandes potências que deverão comandar o jogo geopolítico mundial durante o século XXI: o próprio EUA, a Rússia e a China; e, finalmente, alguns 'respingos' da nova configuração de forças sobre a 'periferia' do sistema. 


\section{O 'racha' americano}

A polarização da sociedade americana e a luta fratricida de suas elites, nesse início do século XXI, devem prosseguir e aumentar de intensidade nos próximos anos, mas não devem alterar a direção, nem a velocidade do crescimento do poder militar global dos EUA. Esse tipo de divisão e luta interna não é fenômeno novo nem excepcional, e se repetiu em vários momentos do século $\mathrm{XX}$, toda vez que foi necessário responder a grandes desafios e tomar decisões cruciais no plano internacional.

Foi o que aconteceu, por exemplo, com a decisão dos EUA de participar das duas grandes guerras mundiais do século XX, e também com a decisão de se envolver e de se retirar das guerras da Coreia e do Vietnã, assim como em vários outros momentos mais recentes da política externa norte-americana, sem que essas divisões tenham afetado ou alterado a 'marcha forçada' dos EUA na direção do 'poder global' que acabou conquistando depois do fim da Segunda Guerra Mundial. outrossim, o mesmo deve acontecer de novo, neste momento, independentemente do que venha a acontecer com o mandato do presidente Donald Trump nos próximos dois anos. Existem dois consensos fundamentais, dentro da elite americana, que se mantêm constantes, e por cima de todas as suas divisões e lutas internas envolvendo seus partidos e facções governantes:

1. no campo das ideias: a convicção de que os EUA devem manter permanentemente sua liderança econômica e militar dentro do sistema mundial;

2. e no campo material: a convicção de que os EUA não podem deixar de financiar a reprodução e a expansão permanente da infraestrutura indispensável ao exercício deste poder global.

Graças a esse consenso fundamental, a 'grande estratégia' dos EUA, no campo internacional, segue sempre em frente, a despeito das 'trepidações internas' da sociedade americana, orientada por dois objetivos fundamentais: i) a 'segurança estratégica' dos EUA, envolvendo a eliminação de toda e qualquer ameaça a seus interesses nacionais, em qualquer ponto do mundo, junto com o controle naval e aeroespacial de todos os 'fluxos' relevantes para o exercício dessa supremacia; ii) com uma ênfase particular na 'segurança energética' dos EUA e de todos os seus principais aliados, por meio do monopólio ou do controle do acesso às principais fontes de energia concentradas em alguns poucos países do sistema mundial.

É a partir desse consenso básico que se deve ler a 'nova doutrina de segurança nacional' do governo de Donald Trump, anunciada no dia 18 de dezembro de 2017 - 28 anos depois da Guerra do Golfo, que inaugurou, em 1991, a ordem mundial do pós-Guerra Fria. Esses documentos oficiais definem periodicamente os principais objetivos estratégicos dos EUA, junto com a identificação de seus principais inimigos e concorrentes, de todo tipo, e em todos os lugares do mundo. Todavia engana-se quem pensar que esse novo documento cumpre apenas com uma obrigação burocrática ou se restrinja às idiossincrasias do presidente Trump. Ele foi preparado, em conjunto, pelo Departamento de Estado, pelo Pentágono, pela Central Intelligence Agency (CIA) e por todas as agências de informação do governo americano, junto com seu Departamento do Comércio e sua Secretaria do Tesouro, e tudo indica que transcenderá o tempo de duração da atual administração norte-americana.

\section{A nova estratégia}

Do ponto de vista estritamente teórico, o novo documento estratégico dos EUA se situa na tradição do realismo internacional de Edward Carr e Hans Morghentau, 
atualizado no fim do século XX pelo 'realismo ofensivo' de John Mearsheimer, que sempre se opôs às teses clássicas do 'cosmopolitismo liberal', introduzidas no cenário internacional pelo presidente americano Woodrow Wilson depois do fim da Primeira Guerra Mundial. Do ponto de vista prático, entretanto, o novo documento norte-americano representa uma ruptura revolucionária com relação ao passado da política externa dos EUA, do século XX, e um gigantesco ponto de interrogação com relação ao futuro dos EUA e de todo o sistema internacional.

A parte mais lida e menos inovadora do texto é exatamente a que define os objetivos estratégicos dos EUA: i) proteger o povo americano e seu modo de vida: ii) promover a prosperidade econômica e a liderança tecnológica americana; iii) preservar a paz mundial por meio da força; e iv) avançar a influência global dos EUA. Bem como a que identifica, logo em seguida, os principais inimigos ou concorrentes dos norte-americanos: i) Rússia e China, as duas grandes 'potências revisionistas' que querem alterar a hierarquia do poder mundial, segundo os norte-americanos; ii) Coreia e Irã, os dois grandes 'Estados predadores' que ameaçam seus vizinhos e o equilíbrio geopolítico do nordeste da Ásia e do Oriente Médio, respectivamente; e, finalmente, iii) o 'terrorismo jihadista' e todo tipo de organização criminosa internacional que propague a violência por meio do tráfico de armas e drogas.

No entanto, a grande novidade da nova estratégia de segurança nacional dos EUA não está em nenhum desses pontos. Está escondida nas entrelinhas do documento no qual aparecem suas premissas e definições fundamentais, que são apresentadas como se fossem uma coisa trivial ou consensual, quando, na verdade, não são, pelo menos na tradição americana. De forma sintética, quase telegráfica, é possível listar os principais pontos em que se sustenta a nova visão do mundo da política externa americana:
I - Os EUA abandonam a ideia do sistema mundial como lugar de uma luta global entre o 'bem' e o 'mal', e o redefinem como um espaço de competição permanente pelo 'poder global', entre Estados nacionais soberanos que seguem sendo o melhor instrumento para a construção de uma ordem mundial pacífica.

II - Os EUA reconhecem que seus valores não são universais e que nada assegura a 'vitória final' dos valores americanos, em um mundo onde cada povo tem sua própria cultura e seus valores éticos particulares.

We will pursue this beautiful vision - a world of strong, sovereign, and independent nations, each with its own cultures and dreams, thriving side by side in prosperity, freedom, and peace $[. .$.$] . We are also realistic and unders-$ tand that the American way of life cannot be imposed upon others, nor is it the inevitable culmination of progress ${ }^{2(I I-4)}$.

III - Os EUA reconhecem, portanto, implicitamente, que não existem 'valores universais', nem existe um 'destino histórico convergente' de toda a humanidade, e, como consequência, desistem do velho projeto messiânico de conversão de todos os povos aos 'valores éticos ocidentais'.

IV - Os EUA declaram explicitamente que, a partir de agora, competirão e negociarão com os demais membros do sistema estatal com base apenas nos seus interesses nacionais, e sempre a partir de uma 'posição de força'.

V - Os EUA, portanto, abrem mão da ideia de uma hegemonia ética e cultural universal e optam pelo uso da força e das armas, se necessário, para impor seus interesses em todos os tabuleiros geopolíticos e geoeconômicos do mundo - mesmo que seja por meio da mudança de governos 
e regimes que sejam considerados uma ameaça política ou econômica aos interesses norte-americanos.

VI - Os EUA, ao mesmo tempo, propõem-se a retomar a liderança mundial do processo de inovação tecnológica em todos os campos do conhecimento e, em particular, no campo da guerra e dos armamentos atômicos. Da mesma forma, assumem seu direito de utilizar sua economia e suas sanções econômicas como instrumentos de guerra.

Em síntese, os EUA estão se propondo a deixar para trás seu 'cosmopolitismo liberal' e sua 'utopia globalista' do século XX, para se converter ao realismo pragmático da velha 'geopolítica das nações' inaugurada pela Paz de Westfália em 1648.

\section{Uma interpretação}

Como explicar essa mudança radical da política externa norte-americana? Do nosso ponto de vista, a partir da própria dinâmica expansiva do sistema interestatal criado pelos europeus há cinco séculos. Expliquemos melhor nossa hipótese e nosso argumento, considerando que a unidade básica do poder territorial do sistema mundial, nesse início do século XXI, segue sendo o 'Estado nacional', com suas fronteiras claramente delimitadas e com sua soberania teoricamente reconhecida pelos demais membros do sistema. Esse 'sistema interestatal' se formou na Europa durante o 'longo século XVI' (1450-1650) - segundo expressão usada pelo historiador francês Fernand Braudel para referir-se às 'longas durações' da história humana -, e desde seu 'nascimento' se expandiu de forma contínua, para dentro e para fora do continente, na forma de grandes 'ondas explosivas' que ocorreram, concentradamente, nos séculos XVI e XIX, e na segunda metade do século $\mathrm{XX}$. Nesses períodos, o sistema estatal europeu conquistou e/ou incorporou o território dos demais continentes, impérios e povos, que foram adotando, aos poucos, as regras de convivência internacional estabelecidas pela Paz de Westfália depois do fim da Guerra dos 30 Anos (1628-1648).

A Paz de Westfália foi assinada por cerca de 150 'autoridades territoriais' europeias, mas só existiam, naquele momento, seis ou sete 'Estados nacionais' na sua forma moderna e com as fronteiras que se mantiveram depois da guerra. Depois das guerras bonapartistas, no início da 'era imperialista' (1840-1914), esse número cresceu graças às independências dos Estados americanos; e, no final da Segunda Guerra Mundial, a carta de criação das Nações Unidas já foi assinada por cerda de 60 Estados nacionais independentes. Contudo foi na segunda metade do século $\mathrm{XX}$ que o sistema interestatal deu um salto e se globalizou aceleradamente, de forma que hoje existem quase 200 Estados soberanos, com direito a um assento nas Nações Unidas.

Contribuíram para esse aumento geométrico: o fim do colonialismo europeu e a independência dos Estados africanos e asiáticos, com destaque especial para a China, que transformou sua civilização e seu império milenar em um Estado nacional, que se integrou definitivamente a todos os organismos e regimes internacionais criados depois da Segunda Guerra Mundial, e depois do fim da Guerra em Fria. Por isso, aliás, muitos analistas americanos falaram, na década de 1990, do 'fim da história' e do nascimento de um mundo unipolar, com a vitória da 'ordem liberal' e a universalização do sistema de valores ocidentais, sob a hegemonia dos EUA.

De fato, nesse período, os EUA alcançaram uma centralidade dentro do sistema mundial e um nível de poder global sem precedentes na história da humanidade, na mesma hora em que se acreditou na vitória do fenômeno da globalização econômica e na universalização das regras e instituições criadas pela ordem liberal do século XX. Ao mesmo tempo, essa mesma expansão do 
poder americano contribuiu decisivamente para o 'ressurgimento' da Rússia, para o salto econômico da China e para a ascensão de várias outras potências regionais, que passaram a utilizar-se das regras do sistema interestatal e de suas mesmas normas, regimes e instituições, para questionar o novo mundo liberal e unipolar americano. Em particular, a Rússia, no campo militar, e a China, no campo econômico. Também o Irã, a Turquia, a Coreia do Norte e vários outros países, que se utilizam hoje da 'diplomacia de Westfália' e da 'geopolítica das nações', inventada pelos europeus, para questionar a própria hierarquia desse sistema liderado pelos EUA.

Do nosso ponto de vista, foram exatamente essa convergência e homogeneização normativa do sistema interestatal, junto com a centralização do poder americano, que levaram ao aumento do poder daqueles Estados que acabaram questionando a 'Pax Americana' a partir da própria retórica, e das próprias regras e instituições criadas e sustentadas pelos norte-americanos. Dessa forma, os EUA decidem abdicar de sua 'universalidade moral' e desistem do velho projeto iluminista de 'conversão' dos povos aos valores da razão e da ética ocidentais. Ao mesmo tempo, abrem mão de sua condição de guardiões éticos e de árbitros de todos os conflitos do sistema mundial; mas atenção, porque os EUA não deixam de considerar que seus valores nacionais são superiores aos demais, e se assumem como um 'povo escolhido' destinado a exercer o poder, por meio da força e da promoção unilateral da divisão e dispersão dos seus concorrentes, de todo tipo. Ou seja, os EUA se assumem como um 'povo escolhido' e abdicam de sua 'universalidade moral', para alcançar a condição de um 'império militar' global. Um império, entretanto, que reconhece a importância dos Estados nacionais e valoriza o sistema interestatal, propondo-se sustentar uma competição permanente com as outras grandes potências, em uma luta que não terá árbitros nem posições neutras, e onde todas as alianças e guerras serão possíveis, em qualquer momento e lugar. Um sistema em que cada país terá que fazer valer seus interesses nacionais por si mesmo, mediante $o$ aumento contínuo do seu poder econômico e militar, e por intermédio de uma corrida tecnológica que deve levar a humanidade a um patamar sem precedente de inovação armamentista.

\section{Rússia e China e o futuro}

Dessa perspectiva, é muito difícil acreditar no sucesso final da aproximação ou acordo entre EUA e Rússia proposto por Donald Trump, durante sua campanha eleitoral, e que deu seus primeiros passos concretos na reunião entre Donald Trump e Vladimir Putin, realizada na cidade de Helsinki, em julho de 2018. O presidente Barack Obama já havia concebido a mesma mudança de rumo no início do seu primeiro mandato, mas foi prontamente demovido desse seu objetivo inovador, pelo establishment americano e por seu próprio partido. Esse projeto exigiria da Rússia a aceitação e legitimação do poder global americano, e envolveria, como contraparte, a aceitação norte-americana da existência de áreas compartidas e/ou exclusivas de influência ou controle russo. Além disso, a aproximação entre esses dois países deixaria vago o lugar ocupado pela Rússia nesse último século e meio, como 'inimigo principal' da estratégia asiática da Inglaterra, na segunda metade do século XIX, e da estratégia global dos EUA, na segunda metade do século $\mathrm{XX}$. O mesmo inimigo comum que cumpriu, durante quase dois séculos, o papel de organizador e hierarquizador dos objetivos estratégicos e do planejamento militar das duas grandes potências anglo-saxônicas e, em menor grau, também da França e da Alemanha, dentro da Europa. Por isso, hoje de novo, sem o 'inimigo russo', o 'império militar' americano perderia sua 'bússola' e teria que sucatear parte importante de sua infraestrutura global que foi construída com 
o objetivo específico de conter, enfrentar e derrotar a Rússia, envolvendo um investimento em recursos materiais e humanos absolutamente gigantesco.

O ingresso da China é a grande novidade do sistema interestatal nas duas primeiras décadas do século XXI e representa, de fato, uma ameaça de médio prazo à supremacia econômica e militar dos EUA no Leste Asiático e na Ásia Central. Ademais, deve-se reconhecer que hoje o sistema de estados e economias nacionais da Ásia está cada vez mais igual ao velho modelo europeu de acumulação de poder e de riqueza, que foi a verdadeira origem do nosso sistema internacional e capitalista. A Ásia é a zona de maior dinamismo econômico do mundo, e é no Leste Asiático que está em curso a luta mais intensa e explícita por uma hegemonia regional, envolvendo a China, o Japão e a Coreia, mas também a Rússia e os EUA, em uma competição que deverá ser o embrião da luta pelo poder global da segunda metade do século XXI.

Muitos analistas costumam anunciar um grande confronto 'hegemônico' entre os EUA e a China. Entretanto, o mais provável, do nosso ponto de vista, é que não ocorra nada disso, e que o sistema mundial atravesse um prolongado período de grandes turbulências e guerras provocadas por mudanças súbitas e inesperadas, e por alianças cada vez mais instáveis, como se todo o mundo estivesse reproduzindo agora, e em escala planetária, o que foi a história passada de formação da própria Europa. Sobretudo porque a China ainda não é uma ameaça global, e ainda não foi transformada no foco central da 'grande estratégia' norte-americana porque ainda não dispõe da capacidade atômica russa de enfrentar o poder militar e atingir seriamente o território americano.

É muito difícil de fazer previsões em um momento de grande ruptura e mudança, ainda mais com relação a uma estratégia como a norte-americana, que se distingue por sua imprevisibilidade radical. Assim mesmo, é possível formular algumas conjecturas a partir da experiência histórica passada. Desse ponto de vista, é possível prever que:

i. a nova estratégia americana de desconstrução dos velhos parâmetros ideológicos e morais, e de questionamento das antigas alianças e lealdades, deve provocar uma grande fragmentação dentro do sistema interestatal, com a multiplicação dos seus conflitos locais, em que os EUA estarão sempre estimulando as divisões internas de cada país e de cada região;

ii. essa mesma fragmentação deve alcançar um nível muito mais grave e incontrolável no Leste da Ásia e na Europa, onde deverá reacender o militarismo do Japão e da Alemanha;

iii. e que esta guerra contínua e fragmentada deve alimentar e realimentar uma corrida tecnológica e armamentista sem precedentes entre os três grandes 'jogadores' e produtores/fornecedores de armas deste novo caleidoscópio mundial: EUA, Rússia e China.

Está cada vez mais claro que o centro nevrálgico da nova competição geopolítica mundial envolverá pelo menos duas potências - Estados Unidos e China - que são cada vez mais complementares de ponto de vista econômico e financeiro e que hoje já são indispensáveis para o funcionamento expansivo da economia mundial. Além disso, o novo eixo da geopolítica mundial deve envolver cada vez mais três Estados 'continentais' - os Estados Unidos, a Rússia e a China - que detém, em conjunto, cerca de um quarto da superfície territorial do mundo e mais de um terço da população global3(39).

Assim mesmo, mantém-se a grande dificuldade de saber e prever o que venha a ser exatamente o 'interesse nacional americano’ em um momento histórico em que a 
sociedade e o establishment político dos EUA aparecem divididos e radicalizados. Donde se possa também concluir que durante este período de grande turbulência que se anuncia pela frente, a direção do poder global dos EUA fique cada vez mais nas mãos do seu comando militar, com suas 700 ou mais bases distribuídas ao redor do mundo, somadas aos seus acordos de 'ajuda' e/ou 'defesa-mútua' com cerca 140 países, dentro de todo o sistema internacional.

Essa nova estratégia dos EUA pode ser revertida? É muito difícil prever, porque ela é o produto de uma luta interna que ainda não acabou. Contudo o mais provável é que se mantenha no futuro, mesmo depois da administração Trump, a menos que haja uma mudança na 'configuração de forças' do sistema mundial. O problema, entretanto, é que para que tal mudança possa acontecer, as demais potências terão que seguir a mesma cartilha dos americanos, e este é um caminho que aponta, inevitavelmente, para um horizonte de 'guerra contínua'.

\section{Na 'periferia' do sistema}

Um tipo de guerra fragmentada e contínua que deve ser travada sobretudo nas regiões mais estratégicas da periferia do sistema mundial; um tipo de guerra que não envolve necessariamente bombardeios, nem o uso explícito da força, porque seu objetivo principal é a destruição da vontade política do adversário, por meio do colapso físico e moral do seu Estado, da sua sociedade e de qualquer grupo humano que se queira destruir. Um tipo de guerra no qual se usa a informação mais do que a força, o cerco e as sanções mais do que o ataque direto, a desmobilização mais do que as armas, a desmoralização mais do que a tortura. Por sua própria natureza e seus instrumentos de 'combate', trata-se de uma 'guerra ilimitada' no seu escopo, no seu tempo de preparação e na sua duração. Uma espécie de guerra infinitamente elástica, que dura até o colapso total do inimigo, ou então se transforma em uma beligerância contínua e paralisante das forças que se dividiram e foram jogadas umas contra as outras, por fatores internos, mas com a contribuição decisiva da potência interventora.

Nesse novo contexto, a própria defesa da democracia e dos direitos humanos - que marcou a última década do século passado perdeu relevância, porque são intervenções que não têm limites éticos. Além disso, esta nova guerra não tem nenhum compromisso com a reconstrução do 'adversário', como aconteceu, por exemplo, com a reconstrução do Japão e da Alemanha, e com o próprio Plano Marshall, destinado à reconstrução europeia, depois do fim da Segunda Guerra Mundial. Não está mais garantido nem mesmo o acesso privilegiado ao mercado interno dos EUA, como ocorreu com Coreia, Japão e vários outros países destruídos e depois ajudados pelos EUA. O que tem sido oferecido na situação atual é apenas o cardápio básico das reformas e políticas neoliberais.

Por analogia, muitos analistas falam de uma nova Guerra Fria, ou de uma Terceira Guerra Mundial, quando se referem a este estado de guerra intermitente e contínuo do século XXI. O importante, entretanto, é compreender que o fenômeno da guerra adquiriu novo significado e nova duração dentro do sistema internacional, e dentro da estratégia de poder global dos EUA. Em grande medida, graças à própria necessidade endógena de reprodução e expansão contínua do 'império militar' americano, que foi construído durante a segunda metade do século $\mathrm{XX}$, mas que se expandiu significativamente depois do fim da Guerra Fria.

O espaço desse novo tipo de império americano não é contínuo nem homogêneo. Seu poder apoia-se no controle de estruturas transnacionais, militares, financeiras, produtivas e ideológicas de alcance global, mas não suprime os estados nacionais nem elimina a 
hierarquia do sistema interestatal. Reconhece a existência de Estados que são seus adversários estratégicos, e exerce seu poder de maneira diferenciada com relação aos demais: vassalagem, no caso de alguns países do Leste Asiático e do Oriente Médio; hegemonia no caso dos seus aliados europeus. Só no caso da América Latina o poder imperial americano é exercido sobre o um território contínuo4(63).
Seja como for, é muito importante que se entenda, sobretudo no caso dos que vivem na 'periferia norte-americana', que acabou definitivamente o tempo da 'hegemonia benevolente', com seu compromisso irrestrito e universal com a democracia, e com sua proteção seletiva de alguns casos de desenvolvimentismo e bem-estar social. E já não é mais possível retornar.

\section{Referências}

1. Fiori JL. História, estratégia e desenvolvimento. São Paulo: Boitempo; 2014.

2. Presidency of the United States. National Security Strategy of the United States of America. Washington, DC; 2017.

\footnotetext{
Fiori JL. O poder global e a nova geopolítica das na-
} ções. São Paulo: Boitempo; 2007.
4. Fiori JL. Sistema mundial: império e pauperização. Fiori JL, Medeiros C, organizadores. Polarização mundial e crescimento. Petrópolis: Vozes; 2001.

\footnotetext{
Recebido em 05/08/ 2018

Aprovado em 09/08/2018

Conflito de interesses: inexistente

Suporte financeiro: não houve
} 